\title{
Growth and developmental outcomes of the extremely preterm infant
}

\author{
Ligia Maria Suppo de Souza Rugolo*
}

\begin{abstract}
Objetive: To provide information for pediatricians and neonatologists to create realistic outcome expectations and thus help plan their actions.

Sources of data: Searches were made of the Cochrane Library, MEDLINE, and Lilacs databases.

Summary of the findings: The assessment of growth and development over the first 2-3 years must adjust chronological age with respect of the degree of prematurity. There is special concern regarding the prognoses of small for gestational age preterm infants, and for those with bronchopulmonary dysplasia. Attention must be directed towards improving the nutrition of extremely low birth weight infants during their first years of life; these infants have high prevalence levels of failure to catch-up on growth, diseases and rehospitalizations during their first 2 years. They are frequently underweight and shorter than expected during early childhood, but delayed catch-up growth may occur between 8 and 14 years. Extremely low birth weight infants are at increased risk of neurological abnormalities and developmental delays during their first years of life. Educational, psychological, and behavioral problems are frequent during school years. Teenage and adult outcomes show that although some performance differences persist, social integration is not impaired.

Conclusions: The growth and neurodevelopment of all ELBW infants must be carefully monitored after discharge, to ensure that children and their families receive adequate support and intervention to optimize prognoses.
\end{abstract}

J Pediatr (Rio J). 2005;81(1 Suppl):S101-S110: Extremely low birth weight, prematurity, growth, catch-up growth, developmental outcome.

\section{Introduction}

\section{The importance of the problem}

Scientific and technological advances during the last twenty years have been associated with great changes in obstetric and neonatal care. Two of these changes that are of special note are the increased use of antenatal corticoid and surfactant replacement therapy for premature newborns. The benefits of both interventions to the

* PhD. Assistant professor, Department of Pediatrics, School of Medicine of Botucatu, Universidade Estadual de São Paulo (UNESP). Chief of the Neonatal Unit, Hospital das Clínicas, School of Medicine of Botucatu, Universidade Estadual de São Paulo (UNESP), Botucatu, SP, Brazil.

Suggested citation: Rugolo LM. Growth and developmental outcomes of the extremely preterm infant. J Pediatr (Rio J). 2005;81(1 Suppl):S101-S110. reduction of neonatal mortality are unquestionable. Therefore, both in developed countries and those still in development, there was a significant increase during the 90 s in the survival rates of very low weight preterms, in particular of those weighing less than $1,000 \mathrm{~g}$, i.e. extremely low weight (ELW). At the end of the nineties, in the United States of America, the survival expectancy for premature infants weighing 750-1,000 g and 500-749 g was around $85 \%$ and $45 \%$ respectively; while in Brazil, figures recorded by the Brazilian Neonatal Research Network (Brazilian Neonatal Research Network (Rede Brasileira de Pesquisas Neonatais)) for the same period show survival rates of $66-73 \%$ for the $750-1,000 \mathrm{~g}$ range and $9-44 \%$ for the $500-749 \mathrm{~g}$ weight range. 1,2 
These data show that the survival of ELW premature infants is a reality that needs to be improved in our country and one which gives rise to an important question: what will the quality of life of these small, premature infants be like? The increasing number of studies in the international literature on long-term follow-up and prognosis of extremely premature infants shows that the subject is currently a focus of interest and concern.

\section{Principal questions}

The most prominent parental concerns and questions include: will our baby survive? Will it be normal? Will it always be small? What can be done to improve its progress? Added to these we have a number of other questions about prognosis which need to be clarified so that we can adequately care for and maximize the quality of life of children born with ELW, such as:

- What is and why use corrected age?

- What factors affect growth and development prognosis?

- What are the most common problems with the growth and development of these children?

- What effect does intrauterine growth restriction (IUGR) have on prognosis?

- Do babies with bronchopulmonary dysplasia have worse prognosis?

- Are growth and development disorders temporary or do they last until adulthood?

These are the questions that we aim to answer in this article.

Corrected age, also known as postconceptional age includes an adjustment of chronological age according to prematurity. Assuming that it would be ideal to be born at 40 weeks' gestational age, the number of weeks that were lacking for gestational age to reach 40 weeks should be subtracted from the chronological age, In other words, corrected age $=$ chronological age - ( 40 weeks - gestational age in weeks).

Although it is not yet completely clear up to which point we should correct premature children's ages, the majority of authors recommend using corrected age for evaluating growth and development until 2 years of age, in order to create real expectations for each child, without underestimating premature children when comparing them with reference standards. When assessing growth, this adjustment is necessary to reduce the variation that results from the rapid growth during the third trimester of pregnancy and the deceleration postpartum, thereby making more accurate evaluations of growth rates and comparisons between different groups of children possible. ${ }^{3}$ Correcting chronological age for prematurity is of fundamental importance to the correct diagnosis of development during the first few years of life, since, for a two-year-old preterm child who was born at 28 weeks, not using corrected age will result in a $12 \%$ difference in performance in tests of development, which is enough for the child to be wrongly classified as abnormal. When dealing with ELW preterms and those born at less than 28 weeks, it is recommended that corrected age be employed until 3 years of age. ${ }^{4}$

\section{Growth}

It is very difficult to predict the ideal growth rate for a preterm newborn because growth is a continuous, complex process that results from the interaction of genetic, nutritional, hormonal and environmental factors. In the case of ELW preterms $(<1,000 \mathrm{~g})$, they have been deprived of a critical period of accelerated intrauterine growth (the third trimester of pregnancy). Added to this is the fact that these small preterms exhibit elevated neonatal morbidity, which results in increased energy expenditure and nutritional requirements whilst also facing seriously restricted nutrient supply and/or ability to benefit from the nutrients available, for which reasons extremely premature infants in neonatal ICUs exhibit cumulative protein and energy deficiencies during the first weeks of life. ${ }^{5}$

The growth dynamic during the neonatal period is characterized by an initial loss of weight, followed by recovery of birth weight. The intensity and duration of these two phases are inversely related to the preterm's gestational age, birth weight and clinical severity. Thus, premature babies weighing less than $1,000 \mathrm{~g}$ generally regain their birth weight at around the week of life and thereafter progress with a growth velocity similar to that of intrauterine life. ${ }^{6}$ This dynamic does not allow them to achieve the body composition of a fetus of the same postconceptional age, and at the point of hospital discharge their anthropometric parameters are well below the minimum percentile of normality on intrauterine growth curves. ${ }^{6-8}$

The expectation with premature newborn babies' growth is that maximum acceleration takes place between 36 and 40 weeks' postconceptional age and that the majority will exhibit catch-up, achieving their growth path within the limits of normality on reference curves by 2-3 years of age. Catch-up is generally achieved first for head circumference, followed by length and then weight. 7,9-10

Very low weight preterms, however, in particular ELW preterms, may well be small children. A number of different studies have shown that such children exhibit slow and late growth recovery with a high risk of inadequate growth during the first years of life. ${ }^{11-13}$ In 1991, Casey et al. had already demonstrated differences in the growth patterns of very low weight preterms during the first 3 years of life, with an absence of catch-up in weight and head circumference, and, although catch-up had taken place with length, this was limited to the first year of life and was insufficient to attain the size expected of a child born full term. ${ }^{14}$

\section{Important concepts}

Catch-up: also called growth recovery or accelerated growth. Characterized by a growth rate that is faster than expected, i.e. accelerated growth velocity, occurring after 
a period of slow or absent growth, allowing a previous deficit to be recovered. In the case of premature children, who generally exhibit weight, length and head circumference below the minimum normal percentile on postnatal growth curves, catch-up growth allows them to match their growth to that of children born full term during the first years of their lives. ${ }^{15}$ It is considered that, completing catch-up, preterms have regained their growth potential. Catch-up can be defined as a variation in $z$ score greater than or equal to 0.67 , which is equivalent to climbing up through the percentile curve paths. 16

Failure to thrive: this is inadequate growth during the first years of life when the child's progress is evaluated against a standard growth curve. It is generally defined as weight below the 5 th percentile of the NCHS curve over 2 or more assessments or when the child fails to maintain the expected rate of weight gain and drops through the growth paths to a level 2 percentiles below previous assessment results. ${ }^{17-18}$ Care should be taken before making this diagnosis during the first 2 years of life since around $25 \%$ of normal children will exhibit a growth deceleration, change their growth percentile path and then continue growing normally, whereas those that present true failure to thrive have a greater risk of growth, development and behavior problems over the long term. 17,19

\section{Factors that influence growth}

In addition to prematurity, certain other factors also influence a child's growth, with the most significant being:

- Genetic potential, represented by the parents' stature. This is the factor that guides the child's final size when an adult.

- IUGR. This has a strong influence on the postnatal growth pattern over both the short and long term and is associated with future diseases in the adult.

- Complications and diseases of prematurity, in particular bronchopulmonary dysplasia, but also severe necrotizing enterocolitis and chronic neuropathy, resulting from periventricular leukomalacia or severe periventricularintraventricular hemorrhage. These factors are responsible for elevated morbidity and compromised nutrition and growth during the first years of life, but their long-term repercussions have not yet been established.

- Nutritional support after hospital discharge. This factor is of fundamental importance and merits special attention because intervention is possible. Nutritional optimization for premature infants, whether through the use of fortified breastmilk or special formulae for post-discharge use, aid catch-up. However, in our country, nutritional status after hospital discharge is worrying since early weaning is common among small premature infants who have spent long periods in hospital and the special formulae for usage post-discharge are not available on the domestic market. This being the case, there is a large chance that these premature babies will receive inadequate nutrition after discharge, which is a significant risk factor for failure to thrive. ${ }^{17,20-21}$

\section{How to assess growth}

Growth is manifest via changes in anthropometric measurements: weight, length, head circumference, middle-upper arm circumference. The relationship between these measurements indicates the proportionality of growth, particularly the relation weight/length during the first 2 years of life and body mass index (BMI - weight/ stature $)^{2}$ from 2 years onwards and are therefore useful for monitoring whether growth is adequate or not. The BMI allows the identification of children whose weights are below what would be expected for their statures (BMI < 5th percentile), but it has been more highly prized for identifying overweight (BMI $\geq 95$ th percentile) and the risk of overweight as defined by BMI between the 85 th and 95th percentiles. $22-23$

For parents and families, initial concern is with the child's weight and later, when school aged, with stature. For physicians, however, it is always important that growth is harmonized and, in this context, head circumference merits special attention during the first years, since its catch-up occurs early, generally by 12 months' corrected age. ${ }^{9}$ Several authors warn of worse prognosis for development in cases of inadequate, or even exaggerated, growth in head circumference during the first months of life. ${ }^{9,24-26}$

Growth should not be assessed on the basis of a single evaluation since the anthropometric measurements taken at any given age only characterize the child's growth status. In particular with respect of premature children it is very important to monitor the growth rate over the first years of life by means of periodic anthropometric measurements assessed for progress along standard, age and sex specific, curves that are generally expressed in percentiles. The growth curves that are most used currently are the CDC/ NCHS-2000 curves. ${ }^{22-23}$ Premature children whose growth curves do not approach the curves for minimum normal limits, exhibit flattening or even go into reverse need to be investigated. Studies of growth generally evaluate patients using z-scores which allows the distance from the average for the normal population to be calculated. Values for normality vary, in half-point increments from -2 to +2 . A zscore of -2 corresponds to percentile $3, z=0$ corresponds to the 50th percentile and $z=+2$ is equivalent to the 97 th percentile on the relevant CDC/NCHS 2000 growth curve. ${ }^{22}$

\section{Premature children at greater risk of growth disorders}

Among those premature children who are at risk of growth problems, those with bronchopulmonary dysplasia stand out as suffering from a concentration of factors that compromise growth. These include increased respiratory work, hypoxemia episodes, postnatal corticoid, reduced liquid intake, nutritional difficulties and inadequacies and elevated respiratory and infectious morbidity during the first years of life with frequent hospital re-admissions. In 
keeping with this, a number of different studies demonstrate that very low weight premature children with bronchopulmonary dysplasia exhibit inadequate growth during their first 2-3 years of life. ${ }^{27-28}$ A recent study of ELW preterms with bronchopulmonary dysplasia, recorded that, during their first year of life, they exhibited growth deficiency with no catch-up in weight and abnormal body composition, with reduced lean and fat mass content. ${ }^{29}$

A wide-ranging, multicenter study assessing the effects of bronchopulmonary dysplasia on long term growth, involving very low weight premature children assessed at 8-10 years of age, found lower weight and head circumference among children who had had dysplasia. However, when confounding variables were controlled (gestational age, birth weight, postnatal disease, neurological sequelae and sociodemographic factors) differences in growth disappeared, suggesting that the inadequate growth of children with bronchopulmonary dysplasia could be associated with a number of other factors and not necessarily the disease itself. ${ }^{30}$ In keeping with these findings, the majority of studies did not find evidence of differences between preterms who did and who did not have bronchopulmonary dysplasia, at preschool and school ages. 31,32

Korhonen et al. assessed growth and adrenal function in children born at very low weights (with and without bronchopulmonary dysplasia). At 7 years of age, the very low birth weight children were smaller and had higher levels of adrenal androgens than those born full term, but there were no differences in growth and adrenal function between those with and without bronchopulmonary dysplasia. 33

Postnatal corticoid is a risk factor for worse growth and development prognosis, which must be taken into account when evaluating the growth of preterms with bronchopulmonary dysplasia. While the greatest concern is currently focused on the adverse effects of corticoid in long-term development, it is already well documented that postnatal corticoid compromises linear growth, whether because of a direct effect on collagen metabolism or by indirectly acting on insulin-like growth factor and its binding protein, in addition to affecting bone mineral metabolism increasing osteoclast activity and reducing osteoblast function. Thus, a prolonged course of systemic corticoid has been associated with inadequate growth in ELW preterms during their first years of life. 34,35

Differences between the studies in terms of the definition and treatment of bronchopulmonary dysplasia, the period studied and the follow-up period together with small sample sizes involving very low weight and/or ELW preterms are all limiting factors that need to be considered when interpreting studies of the effects of dysplasia on premature children's growth. Further studies are needed to evaluate the impact of this disease on those ELW preterms that are surviving nowadays.

Another group of premature children that deserve attention is made up of those who are born small for gestational age, due to the possible additional deleterious effect of IUGR on the postnatal growth of preterms, for which evidence has been found in a number of different studies, although the results are not uniform. ${ }^{11,36-40}$

Intrauterine growth restriction is a common pathological condition, especially in developing countries, and has awakened great concern because of its association with future diseases of adulthood, such as : arterial hypertension, diabetes, hyperlipidemia and coronary disease. ${ }^{41}$ Although a majority ( $80 \%)$ of babies born with IUGR exhibit catch-up growth during the first 2 years of life, generally during the first 6 months, there is great concern for those that do not catch up, since these children have a worse prognosis for intellectual development 42 and half of them will also become adults of small stature. ${ }^{43}$

It should be remembered that the majority of studies of the prognosis of babies born with IUGR are based on full term babies and that the results are contradictory. Some studies suggest that catch-up is beneficial to them during childhood, reducing the risks of hospital admission and death, ${ }^{44}$ while others warn that accelerated growth during the first 2 years of life can have undesirable consequences for the health of the child with an increased risk of obesity during childhood and adult life. $16,45,46$ The mechanism that controls catch-up in babies born with IUGR is not yet clear, but it has been detected that these children exhibit increased food intake and that leptin appears to be involved. The concentration of leptin in umbilical cord blood has a direct relation with weight index at birth and an inverse relationship with weight gain during childhood. Therefore, in babies born with IUGR, the low concentration of this hormone at birth may trigger catch-up by reducing the inhibitory effect of satiety. The possibility that the same factors involved in catch-up contribute to the pathogenesis of the diseases of adulthood reinforces the hypothesis of the fetal origin of these diseases. ${ }^{16}$

These effects have not yet been documented in the specific case of very low weight preterms with IUGR, but it is already very well documented that premature infants born small for their gestational age exhibit worse growth prognosis over both the short and long term when compared with those born at weights adequate for gestational age. Although many of them catch up, there is an increased risk that these children will progress with failure to thrive during their first years of life. ${ }^{17}$

When the growth and development of very low weight preterms born small for gestational age were compared with two different groups of preterms with adequate weights, one group paired by birth weight (with lower gestational ages) and the other by gestational age (with greater birth weights), it was found that those that were born small for gestational age progressed with worse growth rates for weight, length and head circumference, over their first 5 years of life, irrespective of perinatal complications. Cognitive development was worse for the group with least gestational age and was related to the presence of neonatal complications. ${ }^{39}$ These results are an alert to the deleterious effects of IUGR on postnatal growth, whilst showing that neurodevelopment is primarily related to gestational age. 
It is common that premature ELW infants born small for their gestational ages catch up during their first 3 years of life, occurring in around $80 \%$ of cases for length and head circumference and $70 \%$ for weight, as documented in a study by Monset-Couchard \& Bethman, which also showed $7 \%$ of no catch-up, which situation is associated with the presence of diseases and low socioeconomic conditions. ${ }^{40}$ One aspect peculiar to this study was the presence of 37 sets of twins/triplets. In a subsequent study, 36 pairs of premature infants less than $1,000 \mathrm{~g}$ in which one sibling was small for gestational age and another was appropriate for gestational age were studied with the aim of investigating the role of IUGR and the postnatal environment on the growth, development and academic performance of these children. Up until 6 years of age those that had been small for gestational age had weight, stature and head circumference measurements significantly below those of their appropriate for gestational age siblings. From 6 to 17 years of age the growth differences reduced, but remained significant and those born small for gestational age also exhibited a higher frequency of visual, behavioral and language problems. These results showed that the effect of IUGR was more important than the postnatal environment to the growth and development of the children studied. ${ }^{47}$ An analysis of these two studies in conjunction warns that the occurrence of catch-up during the first years is not enough to guarantee adequate growth over the long term.

\section{Growth prognosis for ELW preterms up to adolescence and adulthood}

During childhood, premature children born with ELW are generally smaller and weigh less than children born to full term. However, such preterms may exhibit late catch-up growth between 8 and 14 years of age, and during adolescence their z-score values generally fall within the limits of normality, with a clear relationship between the stature of the adolescent and the stature of their parents. Even so, compared with subjects born with weights $>2,500$ $\mathrm{g}$, adolescents born with ELW are smaller with differences of $5-6 \mathrm{~cm}$ in stature and $8-9 \mathrm{~kg}$ in weight. Around $10 \%$ will exhibit weight and height below the 3rd percentile, differences are not observed in terms of sexual maturity or body composition. $13,48,49$

The fact that ELW children progress with smaller stature until adolescence leads to questions about the possibility of growth hormone use, but in few studies has bone age been tested and when hormone has been used results have been inconclusive. ${ }^{13,40}$ There is not currently enough evidence to recommend this treatment.

It is possible for growth to continue into adulthood and so in order to establish a final prognosis for ELW preterms it is necessary for follow-up to continue for greater periods, until 20 years of age. This being so, a pioneering study by Doyle et al. merits attention. The growth of a cohort of 42 ELW preterms was periodically monitored from birth until 20 years of age and the results were encouraging. When assessed by z-score, the children were smaller (by weight and stature) than the population average until 8 years of age. From 14 years onwards they had achieved the average weight expected and their stature correlated with that of their parents. At 20 the difference in stature from the population average was just $3.5 \mathrm{~cm}$ for men and $3 \mathrm{~cm}$ for women. One important result that merits further investigation was the occurrence of overweight among $1 / 3$ of the cohort with obesity at $10 \% .49$

\section{Development}

The increased survival rates among ever smaller and less mature preterms imposes questions about the future quality of life of these little ones, the ethical aspects of investment limitations, the elevated cost of neonatal care and the economic and social costs of the post-discharge care of babies with sequelae. These concerns have been widely expressed in the literature and follow-up studies of preterms show that the rates of neurodevelopmental problems have not changed significantly in recent years, with high rates of sequelae among ELW preterms, especially those smaller than $750 \mathrm{~g}$ and born at gestational ages of 25 weeks or less. $35,50-52$

\section{Risk factors and prognosis predictors for neurodevelopment}

It is not easy to predict the development prognosis of ELW preterms because it depends on a complex interaction of biological and environmental factors acting on the immature and vulnerable brains of these children. A number of different studies have identified risk factors for neurodevelopmental abnormalities, but the results obtained so far are not unanimous and there is no single factor that can predict a child's development in isolation. ${ }^{9,51-53}$ The primary risk factors indicated by the literature can be grouped thus:

- Biological factors: gestational age $\leq 25$ weeks; birth weight < $750 \mathrm{~g}$; serious abnormalities on ultrasound brain scans (periventricular leukomalacia, periventricular-intraventricular hemorrhage degrees 3 and 4, hydrocephalus); severe neonatal morbidity, especially bronchopulmonary dysplasia; postnatal corticoid use and abnormal head circumference at discharge.

- Environmental factors: low socio-economic status; drug abusing parents.

The most prominent of the biological risk factors is severe abnormalities on ultrasound during the neonatal period which have been shown to have a strong correlation with cerebral palsy. ${ }^{54}$

On the other hand, there are also protective factors, such as effective family participation and the temperament of the child itself, which can modulate prognosis, minimizing stress, helping the child to overcome difficulties and achieve a good quality of life. ${ }^{55}$ 


\section{How to assess development}

Follow-up of development should be a continuous and flexible process of assessment of the child, including observation of the child during the medical consultation, giving due weight to the parents' opinion, a systematic neurological examination, evaluation of neuromotor development markers and screening tests such as, for example the Denver II test, to identify developmental disorders. 56

During the first year of life, special attention should be given to preterms' motor progress, with assessments of passive tonus, posture, active mobility and muscular strength. Transitory neurological abnormalities involving posture, fine and gross motor control, coordination and balance, reflexes and primarily dystonia (hypertonia or hypotonia) are detected in $40-80 \%$ of cases and disappear during the second year of life. A normal neuromotor examination during the second six months of life is predictive of normal motor development, whilst persistent primitive patterns in terms of tonus, reflexes and posture may be transitory abnormalities or manifestations of cerebral palsy. For this reason diagnoses of cerebral palsy are more accurate during the second year of life, when transitory dystonia disappears. ${ }^{4}, 9$

For diagnosing normal or abnormal development and evaluating the degree of abnormality, there are a number of different development scales which should be used for different age ranges. During the first years of life, the Bayley II and Griffiths scales quantify cognitive development, covering motor, adaptive, personal-social and language domains. The Bayley II scale quantifies the development quotient in 2 areas: psycho-motor and mental, and nowadays is the most often employed for the diagnosis of development during the first 3 years of life. For preschool and school aged children, the Wechsler intelligence scales are recommended. 4,9,57

\section{Difficulties and limitations of studies of long term prognosis and development}

When interpreting data on the prognosis of preterms, it should be taken into account that in the majority of studies the sample is chosen by birth weight (very low weight or ELW), while development is directly related to gestational age. Another aspect worthy of attention is related to the limitations inherent to follow-up studies, including: small sample sizes and, primarily, sample losses during follow-up, the duration of follow-up, variation in ages and evaluation methods and the characteristics of the control group. 58

\section{Prognosis for development during the first years of life}

Severe neurosensory sequelae, including blindness, deafness and cerebral palsy are detected in 6-20\% of ELW preterms, with their frequency being inversely proportional to gestational age. So, among preterms born at 23-25 weeks' gestational age, the incidence of severe sequelae reaches $30 \%$ or more, and half of these micropreterms present sensory abnormalities and/or in their neurodevelopment, but, despite this, the majority of them $(>80 \%)$ are capable of walking and feeding themselves at the end of their second year of life. 50-52,59 These figures have not exhibited significant alterations as the survival of micropreterms has increased over recent years. 4,50

During the first years of life, $20-30 \%$ of ELW preterms present some degree of motor function compromise. Neurosensory deficiencies occur in $7-17 \%$ of cases, with a similar percentage of cerebral palsy. The most frequent problem at this age, however, is retarded cognitive development, detected in $30-40 \%$ of these children by low scores in mental and psychomotor development tests. 4,51,60 For premature children born with gestational ages less than or equal to 25 weeks, the frequency of severe neurosensory and cognitive development disorders reaches almost $50 \% .35$

Low development scores at the start of life can have implications for children's performance at school age, although their predictive value for future development is controversial since cognitive development is influenced by multiple factors, with environmental factors being of especial importance the influence of which accentuates as the child's age increases and, in the absence of severe neurological sequelae, can overcome the effects of the biological factors. This being so, special attention has recently been paid to behavioral disorders in ELW preterms, which can already be detected at 2 years of age, by worse performance on items in the Bayley II scale that evaluate the child's orientation and performance capacity. It has been observed that premature children are more distracted, less attentive and less persistent and this can compromise their future cognitive development. 57

Another aspect that must be carefully evaluated against criteria during the first years of life is language development, since the lower the birth weight and gestational age, the greater the probability of delay in several different stages of language development, including: delays in pre-linguistic markers such as recognizing objects and pictures, obeying verbal commands and executing simple acts by 12 months' corrected age; reduced vocabulary and phrase and sentence forming capacity at 2-3 years. If language delay is detected a possible association with auditory deficiency should be investigated because if this is the case audiological intervention can improve prognosis. 56 Language difficulties can persist until school age and compromise development. 58,61

A recent study, involving 211 ELW premature children ( $46 \%$ with gestational ages $\leq 26$ weeks) showed that during the second year of their lives $42 \%$ exhibited normal development and $18 \%$ had severe sequelae. Motor development was normal in $76 \%$ of cases and cerebral palsy occurred in $11 \%$. Delayed speech was the most common disorder, present in $42 \%$ dos cases. Visual abnormalities occurred in $23 \%$, with a predominance of 
strabismus (12\%) and myopia ( $8 \%)$. Blindness was recorded in $0.5 \%$ and $3 \%$ presented severe auditory deficiency. The frequency of visual abnormalities had an inverse relation with birth weight and gestational age, but the remaining problems did not reduce in line with increasing weight and/or gestational age. 62

\section{Prognosis at school age}

In general, studies of ELW premature infants, reduced after the first years of life. At pre-school age, 5-30\% presented some type of functional limitation to their motor activities, to communication or self care. At school age, many ex-preterms manage normal performance, but, as the intellectual challenges of school increase new neuropsychological, behavioral and learning problems may appear. Rates of neurosensory and cognitive deficiencies, of psychological and behavioral disorders are elevated among schoolchildren born at very low weight and particularly weights below 1,000 g.4,37,58

\section{Cognitive performance}

Children and adolescents born with ELW exhibit worse results in cognition tests, with an average difference of 10 points in intelligence quotient (IQ) when compared with controls, and 11 to $17 \%$ exhibit IQs of less than 70.58 Certain studies have documented worse performance in verbal reasoning tests, with $24 \%$ of lack of accuracy at reading and $48 \%$ of inadequate comprehension when reading, ${ }^{63}$ but the majority of authors point out that very low birth weight children, particularly those born at less than $750 \mathrm{~g}$, exhibit compromise in areas of educational ability which can prejudice their academic performance. ${ }^{58,64-}$ ${ }^{66}$ Extremely low weight preterms most often have problems with mathematics (37\% of children), followed by language difficulties in $24 \%$ and problems reading in $23 \%$; and, in these same three areas, performance is even worse for children born below $750 \mathrm{~g} .{ }^{65}$ These cognitive deficiencies contribute to the high rates of repeated years at school (22$26 \%$ ), requirements for special school (19-22\%) or private tutoring $(11-15 \%){ }^{4}$

\section{Behavioral disorders}

Children born at ELW exhibit an increased risk of behavioral problems, with hyperactivity and attention deficit disorders being most common - present in $21-28 \%$ of cases and possibly the result of prenatal or neonatal injuries to the central nervous system. Difficulties interpreting information, solving problems and with social behavior are more common among ELW children than among the general population, irrespective of cultural factors. $4,58,67$

\section{Other problems}

Fine motor uncoordination, subtle neurological disorders, visual or auditory deficiencies and altered visual-spatial perception can contribute to reduced performance at school, prejudice self-esteem and result in behavioral and social disorders. 4,58

\section{Prognosis for adolescence and adult life}

Among the principal factors that determine poor quality of life, it is neurosensory and cognitive deficiencies that most stand out. This being so it is worrying to find that several studies record that development problems in ELW preterms, detected at pre-school and school age, persist until adolescence and, although some may be attenuated with time, others may be underdiagnosed at early ages. ${ }^{4}$ In a cohort of 79 ELW preterms, born at the end of the seventies and followed-up until 14 years old, it was found that just $46 \%$ exhibited totally normal development at adolescence, $14 \%$ had severe motor visual or intellectual sequelae, moderate deficiencies were present in $15 \%$ and mild ones in $25 \%$ of the cases. Nevertheless, it must be considered that these figures may be different for preterms born more recently. 68

When the academic performance of adolescents who had been born at less than 29 weeks' gestational age was evaluated by means of questionnaires filled out by the adolescents themselves, their parents and their teachers, it was found that the majority of them attended normal schools, had good health, performed well in academic challenges and were optimistic about their future. However, one in every six of these adolescents exhibited motor, sensory, intellectual or behavioral sequelae and needed a special school. 69

Adults who were born at very low weight, when compared with those born at normal weight, demonstrated greater frequency of sensory deficiency $(10 \% \mathrm{x}<1 \%)$, lower average IQ (87 vs. 92), lower educational level (74 vs. $83 \%$ completed high school), but there were no differences between the groups in terms of high risk behavior (smoking, drugs, criminality, sexual activity) and it was even found that alcohol and marijuana consumption was less common among ex very low weight preterms, suggesting that they manage a good level of social integration in adult life. ${ }^{70}$

\section{Conclusions}

Extremely low weight premature children are at risk of growth and development problems.

With respect of growth, they are generally small children in terms of weight and stature, present late catch-up, and even then can remain smaller than expected until adolescence. Between adolescence and adulthood they may achieve normal size with genetic potential having an influence on their final adult stature.

Head circumference catch-up takes place during the first year of life while weight is recovered more slowly.

Intrauterine growth restriction, bronchopulmonary dysplasia and inadequate nutrition after discharge compromise catch-up and can cause failure to thrive during the first years of life. 
Neurodevelopment is more related to gestational age than to birth weight and is influenced by environmental factors. Some problems are early and definitive while others may appear later and develop, but the majority of disorders disappear or are attenuated over time.

Severe neurosensory sequelae, represented by cerebral palsy, blindness and deafness, are identified during the first 2 years of life and predominantly affect the most immature children, born at less than 26 weeks' gestational age.

Delayed cognitive development is the most common abnormality during the first years of life and at school ages educational and behavioral problems predominate.

From adolescence onwards, problems appear to be attenuated, making good social integration possible during adulthood.

The behavior of these children is an important component of their global performance and must be evaluated at all stages of their neurodevelopment.

A good quality home, represented by the family's emotional stability and active participation of the parents can improve the performance of the child and offer good quality of life.

Extremely low weight premature children can have normal lives, but need to be monitored on multidisciplinary follow-up programs which will assess them and through which they and their families will receive all the support necessary to maximize their growth and development, from childhood to adolescence.

The overriding objective of all our investment in these extremely small premature babies is to guarantee their survival with good quality of life.

\section{References}

1. Horbar JD, Badger GJ, Carpenter JH, Fanaroff AA, Kilpatrick S, LaCorte $\mathrm{M}$, et al. Trends in mortality for very low birth weight infants, 1991-1999. Pediatrics. 2002;110:143-51.

2. Leone $C R$, Sadeck LS, Vaz FA, Almeida MF, Draque CM, Guinsburg R, et al. Brazilian Neonatal Research Netork (BNRN): very-low birth weight (VLBW) infant morbidity and mortality. Pediatr Res. 2001;49:405A.

3. Guo SS, Roche AF, Chumlea WC, Casey PH, Moore WM. Growth in weight, recumbent length, and head circumference for preterm low-birthweight infants during the first three years of life using gestation-adjusted ages. Early Hum Dev. 1997;47:305-25.

4. Marlow N. Neurocognitive outcome after very preterm birth. Arch Dis Child Fetal Neonatal Ed. 2004;89:F224-28.

5. Embleton NE, Naomi P, Cooke RJ. Postnatal malnutrition and growth retardation: An inevitable consequence of current recommendations in preterm infants? Pediatrics. 2001;107: 270-3.

6. Ehrenkranz RA. Growth outcomes of very low-birth weight infants in the newborn intensive care unit. Clin Perinatol. $2000 ; 27: 325-45$.
7. Anchieta LM, Xavier CC, Colosimo EA. Crescimento de recémnascidos pré-termo nas primeiras 12 semanas de vida. J Pediatr (Rio J). 2004;80:267-76.

8. Cooke RJ, Ainsworth SB, Fenton AC. Postnatal growth retardation: a universal problem in preterm infants. Arch Dis Child Fetal Neonatal Ed. 2004;89:F428-30.

9. Hack M. Follow-up for high-risk neonates. In: Fanaroff $A A$, Martin RJ, editors. Neonatal-Perinatal Medicine. 6th ed. St. Louis: Mosby; 1997. p. 952-7.

10. Rugolo LM, Bentlin MR, Hashimoto M, Rugolo Jr A, Dalben I, Trindade $C E$, et al. Crescimento de prematuros de extremo baixo peso nos primeiros 3 anos de vida. Anais do XVIII Congresso Brasileiro de Perinatologia e XV Reunião de Enfermagem Perinatal; 2004 novembro 13-16; São Paulo, SP, 2004:253-4.

11. Hack M, Weissman B, Borawski-Clarke E. Catch-up growth during childhood among very low-birthweight children. Arch Pediatr Adolesc Med. 1996;150:1122-9.

12. Geoffrey WF, Doyle LW, Noni MD, Callanan C. Very low birth weight and growth into adolescence. Arch Pediatr Adolesc Med. 2000;154:778-84.

13. Peralta-Carcelen M, Jackson DS, Goran MI, Royal SA, Mayo MS, Nelson KG. Growth of adolescents who were born at extremely low birth weight without major disability. J Pediatr. 2000;136: 633-40.

14. Casey PH, Kraemer HC, Bernbaum J, Yogman MW, Sells JC. Growth status and growth rates of a varied sample of low birth weight preterm infants: a longitudinal cohort from birth to three years of age. J Pediatr. 1991;119:599-605.

15. Forbes GB. A note on the mathematics of "catch-up" growth. Pediatr Res. 1974;8:931-4.

16. Ong KK, Ahmed ML, Emmett PM, Preece MA, Dunger DB. Association between postnatal catch-up growth and obesity in childhood: prospective cohort study. BMJ. 2000;320:967-71.

17. Kelleher KJ, Casey PH, Bradley RH, Pope SK, Whiteside L, Barret KW, et al. Risk factors and outcomes for failure to thrive in low birth weight preterm infants. Pediatrics. 1993;5:941-8.

18. Krugman SD, Dubowitz $\mathrm{H}$. Failure to thrive. Am Fam Physician. 2003;68:879-84.

19. Oates RK, Peacock A, Forrest D. Long-term effects of nonorganic failure to thrive. Pediatrics. $1985 ; 75: 36-40$.

20. Lucas A, Fewtrell MS, Morley R, Singhal A, Abbott RA, Isaacs E, et al. Randomized trial of nutrient-enriched formula versus standard formula postdischarge preterm infants. Pediatrics. 2001;108:703-11.

21. Kuschel CA, Harding JE. Multicomponent fortified human milk for promoting growth in preterm infants. Cochrane Database Syst Rev. 2004;(1):CD000343.

22. Centers for Disease Control and Prevention [homepage on the Internet]. Atlanta, GA: Centers for Disease Control and Prevention [updated 2004 May 20; cited 2005 February 15]. 2000 CDC Growth Charts: United States; [about 3 screens]. Available from: http://www.cdc.gov/growthcharts

23. Kuczmarski RJ, Ogden CL, Grummer-Strawn LM, Flegal KM, Guo SS, Wei R, et al. CDC growth charts: United States. Hyattsville, MD: US Department of Health and Human Services, 2000. NCHS Advance Data Report no 314.

24. Gross SJ, Oehler RN, Eckerman CO. Head growth and developmental outcome in very low birth weight infants. Pediatrics. 1983;71:70-5.

25. Roche AF, Guo SS, Wholihan KM, Casey P. Reference data for head circumference-for-length in preterm low-birth-weight infants. Arch Pediatr Adolesc Med. 1997;151:50-7.

26. Brandt I, Sticker EJ, Lentze MJ. Catch-up growth of head circumference of very low birth weight, small for gestational age preterm infants and mental development to adulthood. J Pediatr. 2003;142:463-8.

27. Vohr BR, Bell EF, Oh W. Infants with bronchopulmonary dysplasia: growth pattern and neurologic developmental outcome. Am J Dis Child. 1982;136:443-7.

28. Wheater M, Rennie JM. Poor prognosis after prolonged ventilation for bronchopulmonary dysplasia. Arch Dis Child. 1994;71: F210-11. 
29. Huysman WA, de Ridder $M$, de Bruin NC, van Helmond G, Terpstra N, van Goudoever JB, et al. Growth and body composition in preterm infants with bronchopulmonary dysplasia. Arch Dis Child Fetal Neonatal Ed. 2003;88:F46-51.

30. Vrlenich LA, Bozynski ME, Shyr Y, Schork A, Roloff DW, McCormick MC. The effect of bronchopulmonary dysplasia on growth at school age. Pediatrics. 1995;95:855-9.

31. Robertson CM, Etches PC, Goldson E, Kyle JM. Eight-years school performance, neurodevelopmental and growth outcome of neonates with bronchopulmonary dysplasia: a comparative study. Pediatrics. 1992;89:365-72.

32. Giacoia, GP, Venkataraman PS, West-Wilson KI, Faulkner MJ. Follow-up of school-age children with bronchopulmonary dysplasia. J Pediatr. 1997;130:400-8.

33. Korhonen P, Hyodynmaa E, Lenko H-L, Tammela O. Growth and adrenal androgen status at 7 years in very low birth weight survivors with and without bronchopulmonary dysplasia. Arch Dis Child. 2004;89:320-24

34. Gibson AT, Pearse RG, Wales JK. Growth retardation after dexamethasone administration: assessment by knenometry. Arch Dis Child. 1993;69:505-9.

35. Wood NS, Costeloe K, Gibson AT, Hennessy EM, Marlow N, Wilkinson AR, for the EPICure Study Group. The EPICure study: growth and associated problems in children born at 25 weeks of gestational age or less. Arch Dis Child Fetal Neonatal Ed. 2003;88:F492-500.

36. Sung IK, Vohr B, Oh W. Growth and neurodevelopmental outcome of very low birth weight infants with intrauterine growth retardation: comparison with control subjects matched by birth weight and gestational age. J Pediatr. 1993;123: 618-24.

37. Hack M, Klein N, Taylor G. School-age outcomes of children of extremely low birthweight and gestational age. Semin Neonatol. 1996; $1: 277-88$.

38. Spinillo A, Capuzzo E, Piazzi G, Baltaro F, Stonati M, Ometto A. Significance of low birthweight for gestational age among very preterm infants. Br J Obstet Gynecol. 1997;104:668-73.

39. Gutbrod T, Wolke D, Soehne B, Ohrt B, Riegel K. Effects of gestation and birth weight on the growth and development of very low birthweight small for gestational age infants: a matched group comparison. Arch Dis Child Fetal Neonatal Ed. 2000;82:F208-14

40. Monset-Couchard M, de Bethmann O. Catch-up growth in 166 small for gestational age premature infants weighting less than $1000 \mathrm{~g}$ at birth. Biol Neonate. 2000;78:161-7.

41. Morley R, Dwyer T. Fetal origins of adult disease? Clin Experim Pharmacol Physiol. 2001;28:962-6.

42. Lundgren EM, Cnattingius S, Jonsson B, Tuvemo T. Intellectual and psychological performance in males born small for gestational age with and without catch-up growth. Pediatr Res. 2001;50:91-6.

43. Botero D, Lifshitz F. Intrauterine growth retardation and longterm effects on growth. Curr Opin Pediatr. 1999;11:340-53.

44. Victora CG, Barros FC, Horta BL, Martorell R. Short-term benefits of catch-up growth for small for gestational age infants. Internal J Epidemiol. 2001;30:1325-30.

45. Eriksson JG, Forsen T, Tuomilehto J, Winter PD, Osmond C, Barker DJ. Catch-up growth in childhood and death from coronary heart disease: longitudinal study. BMJ. 1999;318: 427-31.

46. Lucas A, Fewtrell MS, Cole TJ. Fetal origins of adult disease the hypothesis revisited. BMJ. 1999;319:245-9.

47. Monset-Couchard M, de Bethmann O, Relier J-P. Long term outcome of small versus appropriate size for gestational age co-twins/triplets. Arch Dis Child Fetal Neonatal Ed. 2004:89:F310-4.

48. Saigal S, Stoskopf BL, Streiner DL, Burrows E. Physical growth and current health status of infants who were of extremely low birth weight and controls at adolescence. Pediatrics. $2001 ; 108: 407-15$
49. Doyle LW, Faber B, Callanan C, Ford GW, Davis NM. Extremely low birth weight and body size in early adulthood. Arch Dis Child. 2004;89:347-50.

50. Hack M, Fanaroff AA Outcomes of children of extremely low birthweight and gestational age in the 1990s. Semin Neonatol. 2000;5:89-106.

51. Hack M, Wilson-Costello D, Friedman H, Taylor G, Schluchter $M$, Fanaroff AA. Neurodevelopment and predictors of outcomes of children with birth weights of less than 1000g: 1992-1995. Arch Pediatr Adolesc Med. 2000;154:725-31.

52. Vohr BR, Wright LL, Dusick AM, Mele L, Verter J, Steichen J], et al. Neurodevelopmental and functional outcomes of extremely low birth weight infants in the National Institute of Child Health and Human Development Neonatal Research Network, 19931994. Pediatrics. 2000;105:1216-26.

53. Msall ME, Buck GM, Rogers BT, Merke D, Catanzaro NL, Zorn WA. Risk factors for major neurodevelopmental impairments and need for special education resources in extremely premature infant. J Pediatr. 1991;119:606-14.

54. Wilson-Costello D, Borawski E, Friedman $H$, Redline R, Fanaroff AA, Hack M. Perinatal correlates of cerebral palsy and other neurologic impairment among very low birth weight children. Pediatrics. 1998;102:315-22.

55. Lester BM, Miller-Loncar CL. Biology versus environment in the extremely low-birth weight infant. Clin Perinatol. 2000;27: 461-81.

56. AAP. Developmental surveillance and screening of infants and young children. Pediatrics. 2001;108:192-6.

57. Sajaniemi N, Hakamies-Blomqvist L, Katainen S, von Wendt L. Early cognitive and behavioral predictors of later performance: a follow-up study of ELBW children from ages 2 to 4 . Early Child Res Quart. 2001;16:343-61.

58. Saigal S. Follow-up of very low birthweight babies to adolescence. Semin Neonatol. 2000;5:107-18.

59. Finnstrom O, Olausson PO, Sedin G, Serenius F, Svenningsen $\mathrm{N}$, Thiringer $\mathrm{K}$, et al. Neurosensory outcome and growth at three years in extremely low birthweight infants: follow-up results from the Swedish national prospective study. Acta Paediatr. 1998;87:1055-60.

60. O'Callaghan MJ, Burns Y, Gray P, Harvey JM, Mohay HI, Rogers $Y$, et al. Extremely low birth weight and control infants at 2 years correct age: a comparison of intellectual abilities, motor performance, growth and health. Early Hum Dev. 1995;40: 115-25.

61. Msall ME, Tremont MR. Functional outcomes in self-care, mobility, communication, and learning in extremely low-birth weight infants. Clin Perinatol. 2000;27:381-401.

62. Tommiska V, Heinonen $\mathrm{K}$, Kero $\mathrm{P}$, Pokela ML, Tammela $\mathrm{O}$, Jarvenpaa $A L$, et al. A national two year follow up study of extremely low birthweight infants born in 1996-1997. Arch Dis Child Fetal Neonatal Ed. 2003;88:F29-34.

63. Rickards AL, Kelly EA, Doyle LW. Cognitive, behavioural and academic progress in very low birthweight (VLBW) children to 14 years of age. J Pediatr Child Health. 1998;34:A1.

64. Botting N, Powls A, Cooke RW, Marlow N. Cognitive and educational outcome of very low birthweight children in early adolescence. Dev Med Child Neurol. 1998;40:652-60.

65. Saigal S, Hoult LA, Streiner DL, Stoskopf B, Rosenbaum PL. School difficulties at adolescence in a regional cohort of children who were extremely low birthweight. Pediatrics. 2000;105: 325-31.

66. Bhutta AT, Cleeves MA, Casey PH. Cognitive and behavioral outcomes of school-aged children who were born preterm. JAMA. 2002;288:728-37.

67. Hille ET, Ouden AL, Saigal S, Wolke D, Lambert M, Whitaker A, et al. Behavioural problems in children who weigh $1000 \mathrm{~g}$ or less at birth in four countries. Lancet. 2001;357:1641-3.

68. Doyle LW, Casalaz D, for the Victorian Infant Collaborative Study Group. Outcome at 14 years of extremely low birthweight infants: a regional study. Arch Dis Child Fetal Neonatal Ed. 2001;85:F159-64 
69. Johnson A, Bowler U, Yudkin C, Hockley D, Wariyar U, Gardner $F$, et al. Health and school performance of teenagers born before 29 weeks gestation. Arch Dis child Fetal Neonatal Ed. 2003;88:F190-8.

70. Hack M, Flannery DJ, Schluchter M, Carvar L, Borawski, E, Klein $N$. Outcomes in young adulthood for very low birth weight infants. N Engl J Med. 2002;346:149-57.
Correspondence:

Lígia Maria Suppo de Souza Rugolo

Depto. de Pediatria - Faculdade de Medicina de Botucatu - UNESP

Distrito Rubião Jr.

CEP 18618-970 - Botucatu, SP

Brazil

E-mail: ligiasr@fmb.unesp.br 